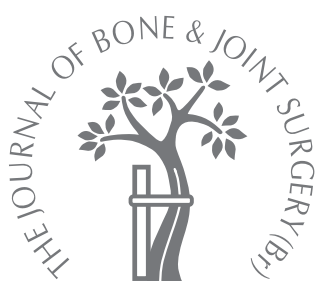

M. J. B. Keel, J. D. Bastian, L. Büchler, K. A. Siebenrock

From the University of Bern, Bern, Switzerland
M. J. B. Keel, MD, FACS General and Trauma Surgeon, Professor of Surgery

J. D. Bastian, MD, Resident in

Orthopaedic Surgery

․ L. Büchler, MD, Consultant

Orthopaedic Surgeon

K. A. Siebenrock, MD

Chairman \& Director

Department of Orthopaedic

Surgery

University of Bern, Inselspital, Freiburgstrasse 3, $\mathrm{CH}-3010$

Bern, Switzerland.

Correspondence should be sent to Dr J. D. Bastian; e-mail: johannesbastian@gmx.de

(C)2010 British Editorial Society of Bone and Joint Surgery doi:10.1302/0301-620X.92B3. $23016 \$ 2.00$

$J$ Bone Joint Surg [Br] 2010;92-B:442-6.

Received 30 June 2009;

Accepted after revision 19

November 2009

\title{
Surgical dislocation of the hip for a locked traumatic posterior dislocation with associated femoral neck and acetabular fractures
}

Traumatic posterior dislocation of the hip associated with a fracture of the posterior acetabular wall and of the neck of the femur is a rare injury. A 29-year-old man presented at a level 1 trauma centre with a locked posterior dislocation of the right hip, with fractures of the femoral neck and the posterior wall of the acetabulum after a bicycle accident. An attempted closed reduction had failed. This case report describes in detail the surgical management and the clinical and radiological outcome. Open reduction and fixation with preservation of the intact retinaculum was undertaken within five hours of injury with surgical dislocation of the hip and a trochanteric osteotomy. Two years after operation the function of the injured hip was good. Plain radiographs and MR scans showed early signs of osteoarthritis with some loss of joint space but no evidence of avascular necrosis. The patient had begun skiing and hiking again.

The combination of fractures of the neck of the femur and of the posterior wall of the acetabulum hampers closed reduction of a posterior dislocation of the hip. Surgical dislocation of the hip with trochanteric flip osteotomy allows controlled open reduction of the fractures, with inspection of the hip joint and preservation of the vascular supply.

Patients with a posterior dislocation of the hip present with adduction, internal rotation, flexion and shortening of the injured limb, and usually require urgent reduction. ${ }^{1-3}$ There are no recommendations in the literature for the treatment of a locked posterior dislocation of the hip with an associated fracture of the acetabulum of the neck and of the femur. This case report describes in detail the surgical management of a traumatic posterior dislocation of the hip with closed reduction hampered by a fracture of the neck of the femur, a fracture of the posterior wall of the acetabulum and a labral tear. Surgical dislocation of the hip is proposed for the treatment of this pattern of injury.

\section{Case report}

A 29-year-old male cyclist was struck by a car in 2007. He had pain in his right leg, which was shortened and locked in internal rotation. At the nearest hospital, radiographs showed a posterior dislocation of the hip. Attempted closed reduction failed. After transfer to a level 1 trauma centre, radiographs and CT scans showed a posterior dislocation with fractures of the neck of the femur and the posterior acetabular wall (Figs 1 to 3 ).
The hip joint was exposed within five hours of the injury by surgical dislocation (Fig. 4). After splitting the iliotibial band, the interval between gluteus maximus and medius was developed. The posterior origin of the vastus lateralis fascia was released and displaced anteriorly. Osteotomy of the greater trochanter began at its posterosuperior tip and ended distal to the lateralis tubercle. The insertions of gluteus medius and vastus lateralis were preserved on the mobile trochanteric fragment, whereas the external rotators remained on the femoral side of the trochanter. The trochanteric fragment was mobilised and displaced anteriorly, and the joint capsule exposed within the interval between piriformis and gluteus minimus. After a z-shaped capsulotomy, ${ }^{4}$ the hip joint was visualised. A fragment of the posterior acetabular wall was attached to the joint capsule and the acetabulum was empty owing to posterosuperior dislocation of the femur (Fig. 4a). The femoral head was gently mobilised. A small fragment of the femoral neck was reduced and fixed with a $2.7 \mathrm{~mm}$ screw. About two-thirds of the retinaculum containing the vessels that perfuse the head was intact. For preliminary fixation of the frac- 


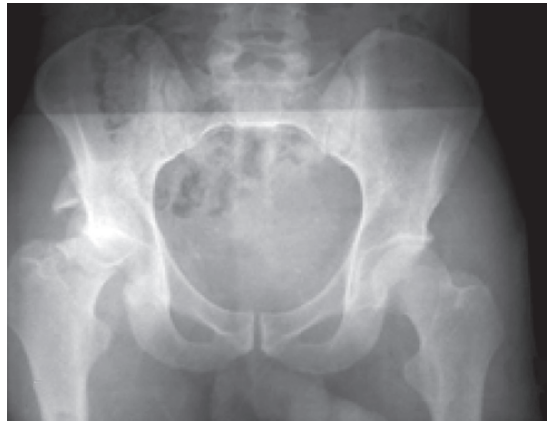

Fig. 1a

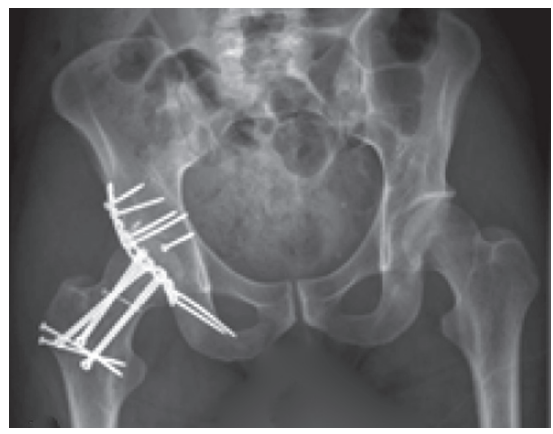

Fig. $1 b$

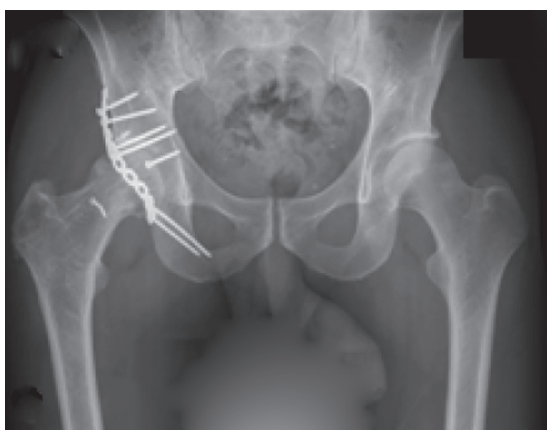

Fig. 1c

Anteroposterior radiographs of the right hip showing (a) a posterior dislocation of the hip with fractures of the neck of the femur and the posterior acetabular wall. (b) Post-operatively showing anatomical reduction of the femoral head, fixation of the neck fracture and reconstruction of the posterior acetabular wall. (c) Two years after operation there are no signs of avascular necrosis, but there are early signs of osteoarthritis with some loss of joint space but no heterotopic ossifications. The screws were removed from the neck and trochanter 18 months after operation.

ture of the neck, two Kirschner (K)-wires were passed through the cut surface of the trochanteric osteotomy into the neck and then into the head (Fig. 4b). The head was gently reduced into the acetabulum. One guide wire was positioned slightly dorsal to the cut surface of the trochanteric osteotomy. Fluoroscopy confirmed anatomical reduction of the fragment of the neck and the associated fracture,

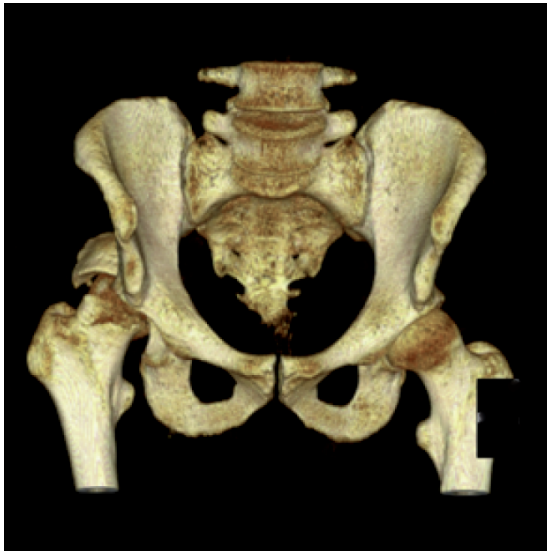

Fig. 2a

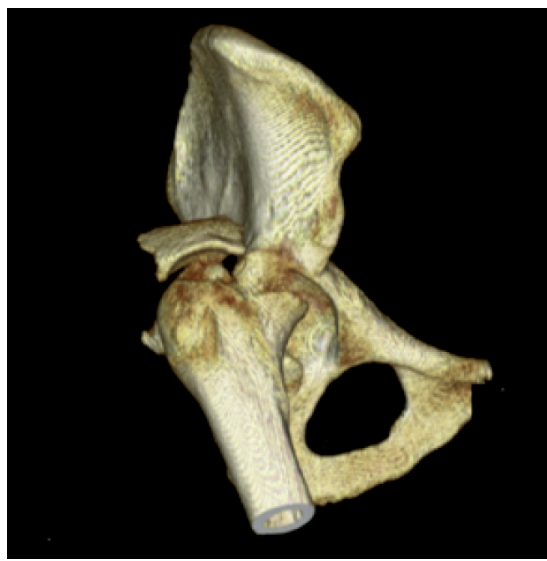

Fig. $2 b$

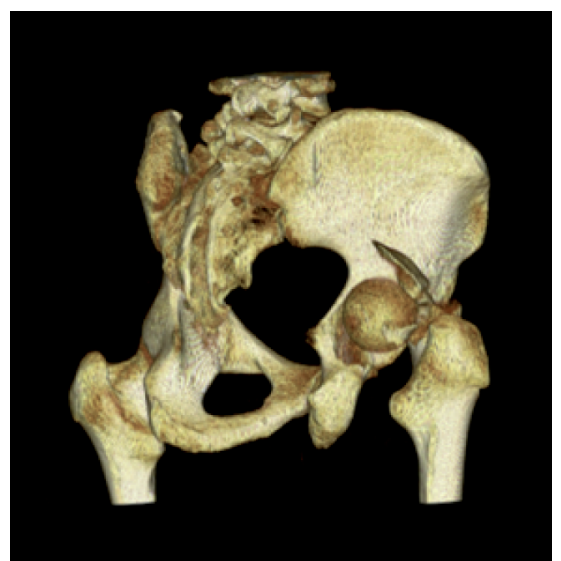

Fig. 2c

Three-dimensional reconstructions of the pelvis, showing the posterior dislocation of the hip with fractures of the medial aspect of the femoral neck and the posterior acetabular wall from (a) anterior, (b) lateral and (c) posterolateral views.

and showedconcentric reduction of the femur into the hip joint. The second guide wire was placed fluoroscopically, and after drilling with a cannulated drill bit and placement 


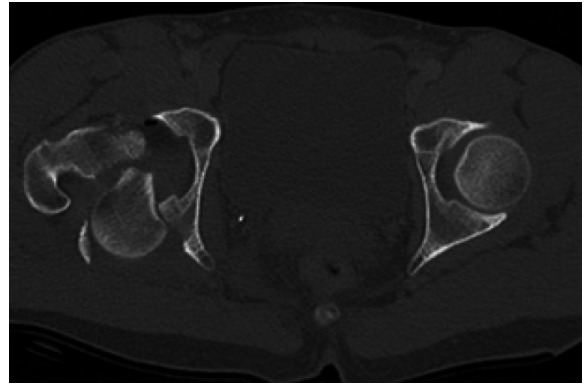

Fig. 3a

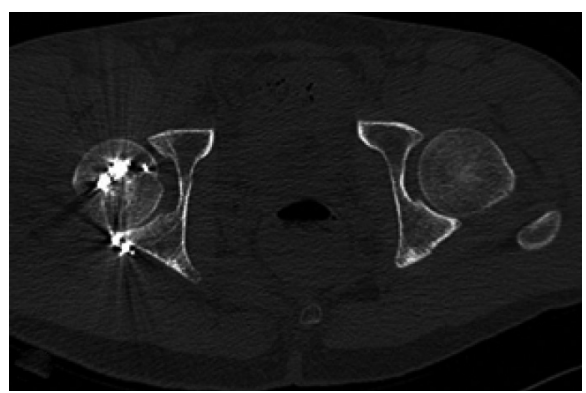

Fig. 3d

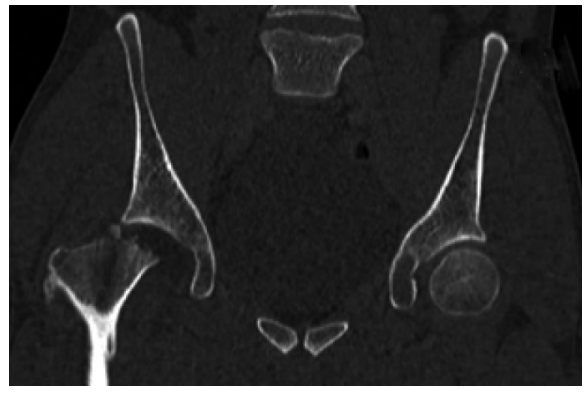

Fig. 3b

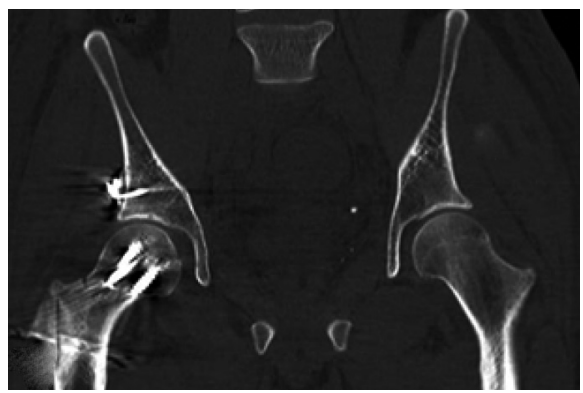

Fig. 3e

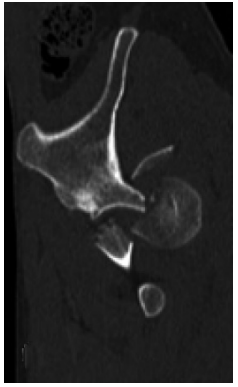

Fig. 3c

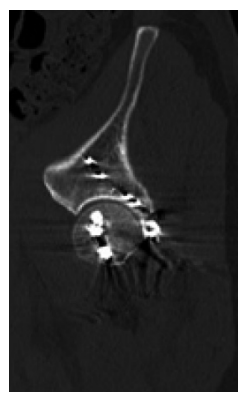

Fig. $3 f$

CT scans of the pelvis and right hip. (a) Axial, (b) coronal and (c) sagittal scans performed before surgery, revealing a locked posterior dislocation with fractures of the neck of the femur and the posterior acetabular wall. (d to f) CT scans performed post-operatively showing anatomical reduction of the femoral neck/head and the acetabular wall fractures.

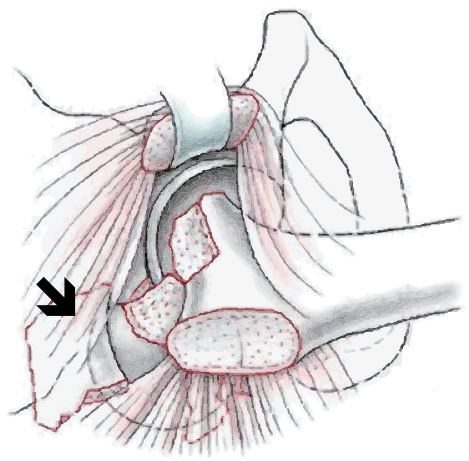

Fig. $4 a$

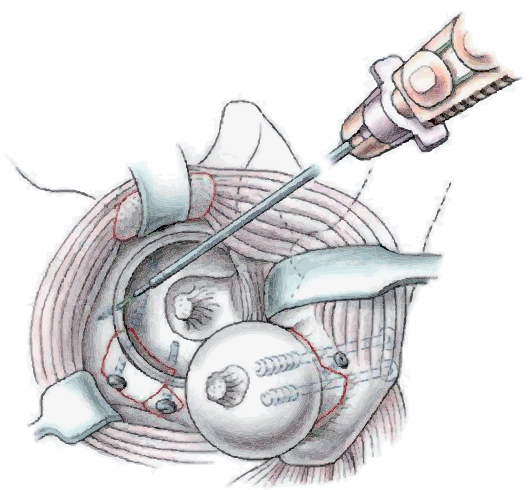

Fig. 4d

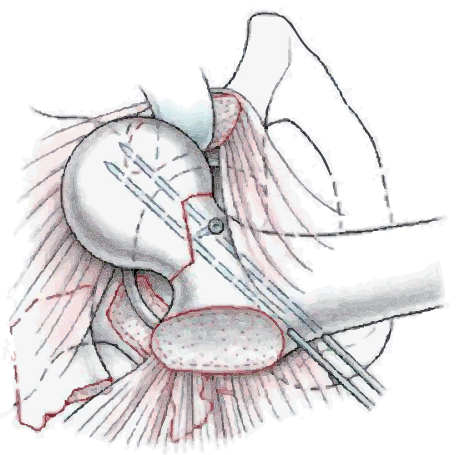

Fig. $4 b$

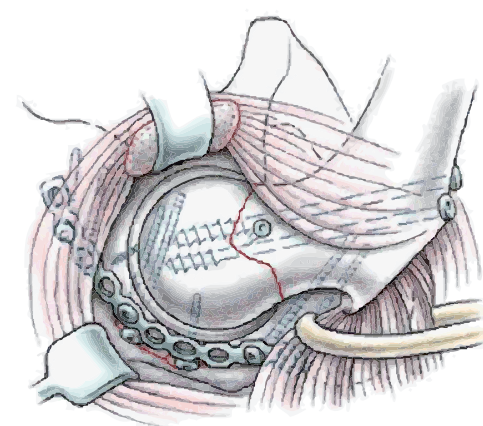

Fig. 4e

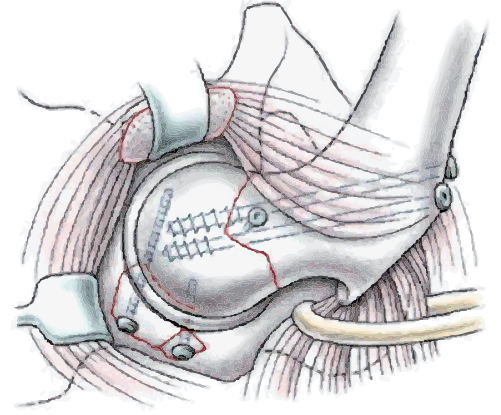

Fig. 4c

Illustration showing visualisation of the hip joint by surgical dislocation of the right hip in a lateral decubitus position. (a) Posterior dislocation of the femoral head with additional fracture of the neck and anterior displacement of the posterior acetabular wall fragment (arrow). (b) Reduction and preliminary fixation of the femoral head to the femoral neck. (c) The fracture of the neck was fixed definitively by cannulated screws and the acetabular rim was reconstructed by fixation of the posterior fragment. (d) Re-attachment of a labral lesion to the acetabular rim using a metal anchor. (e) A ten-hole, $3.5 \mathrm{~mm}$ acetabular reconstruction plate was fixed for additional stability of the posterior wall. The yellow loop elevates the external rotators.

ation of the fracture of the neck. After relocation of the head, the fracture fragment of the posterior acetabular wall of the two $7.3 \mathrm{~mm}$ cannulated screws over the guide wires, the wires were removed. Fluoroscopy confirmed stable fix- 


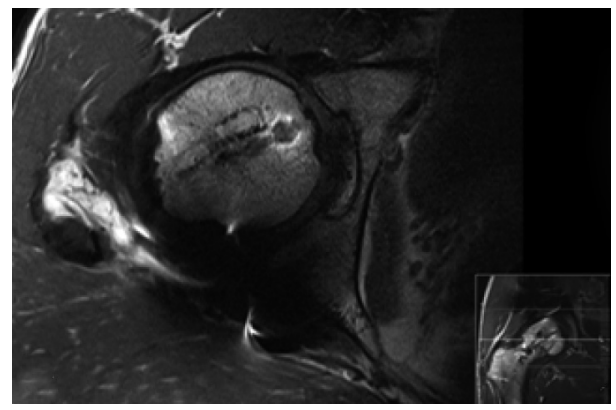

Fig. 5 a

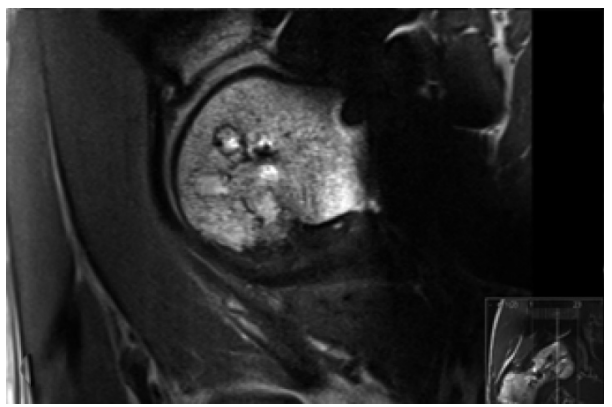

Fig. 5c

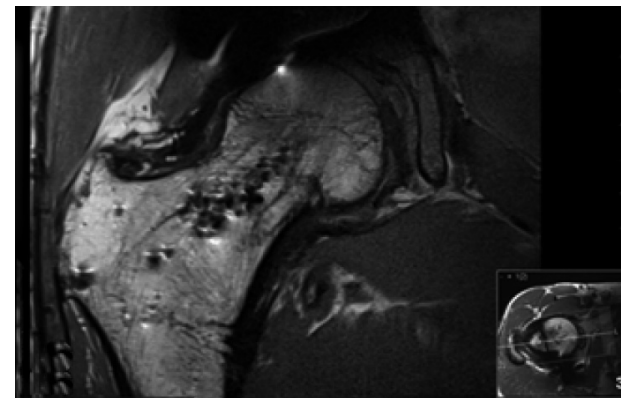

Fig. $5 b$

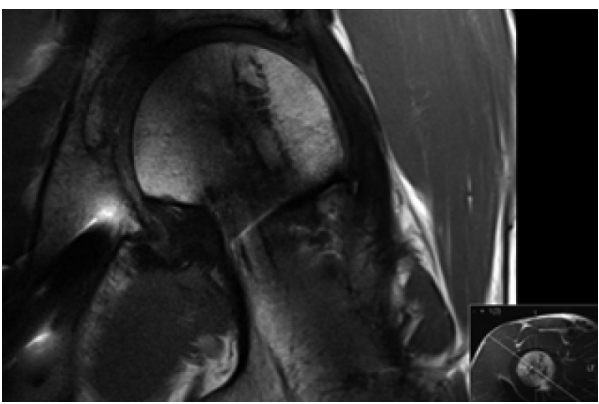

Fig. 5d

MR scans of the right hip. (a) Axial, (b) coronal, (c) sagittal and (d) radial sequences performed two years after operation, showing no signs of avascular necrosis of the femoral head.

was visualised. It was still attached to the periosteal flap and could be held by K-wires before fixation with two lag screws (Fig. 4c). The femoral head was carefully dislocated again for resection of the ligamentum teres and for joint debridement. Repeated drilling with a $2 \mathrm{~mm}$ bit into the superior quadrant of the femoral head showed some bleeding, albeit, with a little delay. A cranial labral lesion was reattached to the acetabular rim using a metal anchor in the dislocated position of the femoral head (Fig. 4d). In the relocated hip, a ten-hole, $3.5 \mathrm{~mm}$ reconstruction plate was fixed for additional stability of the posterior wall (Fig. 4e). The capsule was closed loosely, to allow for evacuation of a haematoma. The trochanteric fragment was reduced and fixed with two $3.5 \mathrm{~mm}$ cortical screws. Before closure of the wound, an additional $7.3 \mathrm{~mm}$ screw was placed in the neck of the femur to increase the stability of the fixation.

The patient was discharged from hospital four days later and mobilisation with partial weight-bearing of $10 \mathrm{~kg}$ continued for three months. The range of movement of the hip was limited to $60^{\circ}$ of flexion without internal or external rotation for the first six weeks.

The screws were removed from the neck of the femur and trochanteric osteotomy 18 months after operation, and six months later plain radiographs and MR scans showed early signs of osteoarthritis, with some loss of joint space (grade I, according to the Tönnis classification ${ }^{5}$ ), but without heterotopic ossification ${ }^{6}$ or evidence of avascular necrosis ${ }^{7}$ (Fig. 5). The Harris Hip Score ${ }^{8,9}$ was 76 of 100 points (pain: 20/44), Western Ontario McMasters score ${ }^{10}$ for pain was $2 / 20$, stiffness of $2 / 8$ and physical activity of $14 / 68$. For the Short form-12 Quality of life score ${ }^{11}$ the patient had a physical score of 50.2/56.6 and a mental score of 48.4/60.8. Although there was episodic discomfort from the hip he was able to participate in impact sports (University of California, Los Angeles Activity score, Level 10 12 ) and one year after operation he started skiing and hiking again.

\section{Discussion}

Posterior dislocation of the hip is a severe injury. Extracapsular vessels can be compressed against the acetabular rim with a high risk of avascular necrosis of the head of the femur. ${ }^{13,14}$ As the frequency of avascular necrosis is related to the duration of dislocation, closed reduction is usually undertaken as an emergency. ${ }^{1,2,15-17}$ However, in some situations closed reduction is impossible because of a locked dislocation, or an anatomical reduction is not obtained. ${ }^{18}$ Reasons for a locked dislocation or a non-anatomical reduction can be the presence of associated fractures of the femoral head or neck, fracture fragments from the acetabulum, a femoral head buttonholed through the capsule, displacement of the piriformis muscle into the acetabulum, labral lesions or osteocartilaginous loose bodies. ${ }^{1,15,18-21}$ We have recently reported a similar case with particular attention being given to the local pathological anatomy and suggested an algorithm for the management of patients with complex patterns of fracture/dislocation of the hip. ${ }^{22}$ Attempted reduction of a locked posterior dislocation may lead to rupture of the superior retinacular vessels arising from the deep branch of the 
medial circumflex artery, which provide the blood supply to the femoral head. ${ }^{15,23}$ The relatively short follow-up may limit the conclusion that avascular necrosis will not occur. However, the mean time before the development of avascular necrosis in fracture-dislocations of the hip is reported to be 17 months. ${ }^{15}$ In this case, MR scans two years postoperatively did not show evidence of avascular necrosis. Furthermore, as the injury itself did not lead to disruption of the retinaculum, the vascular supply to the femoral head was not impaired, as observed intra-operatively and confirmed by local drilling. Also, the operation was performed within six hours of injury, and stable fixation was achieved. Controversy remains regarding the optimal surgical approach for the treatment of fractures of the acetabulum and head of the femur. ${ }^{24}$ The extension of the Kocher-Langenbeck approach by a trochanteric flip osteotomy ${ }^{25}$ offers several advantages, allowing full access to the femoral head and the acetabulum and hence the opportunity to debride the hip joint, ${ }^{25-27}$ and for fixation of fractures of the femoral neck and head ${ }^{28}$ and/ or the acetabulum. ${ }^{26,29}$ Local cartilage damage and perfusion of the femoral head can easily be evaluated, and the labrum re-attached if required. ${ }^{25,30,31}$ However, the most severe potential complication is avascular necrosis. With precise knowledge of the anatomy and careful dissection, ${ }^{23}$ the risk is minima ${ }^{25}$ and did not occur in this case. Cranial migration and/or nonunion of the trochanteric osteotomy with subsequent weakening of the abductor muscles have been major concerns in the past. ${ }^{32,33}$ However, the incidence of these complications has been considerably reduced by the introduction of the trochanteric flip osteotomy, ${ }^{34}$ and have been further reduced by performing a stepped osteotomy, as reported recently. ${ }^{35}$ Further concerns might be prolonged operating time, increased blood loss, or an increased incidence of heterotopic bone formation. Blood loss and operating time using the transtrochanteric and the KocherLangenbeck approaches are comparable. ${ }^{24}$ The incidence of severe heterotopic ossification was not increased in patients who underwent internal fixation of fractures or surgical treatment of femoro-acetabular impingement by surgical dislocation of the hip. ${ }^{24,35}$

Surgical dislocation of the hip allows the simultaneous fixation of acetabular and femoral neck fractures, while preserving the vascular supply to the femoral head.

No benefits in any form have been received or will be received from a commercial party related directly or indirectly to the subject of this article.

\section{References}

1. Thompson VP, Epstein HC. Traumatic dislocation of the hip: a survey of two hundred and four cases covering a period of twenty-one years. J Bone Joint Surg [Am] 1951;33-A:746-78

2. Epstein HC. Traumatic dislocations of the hip. Clin Orthop 1973;92:116-42.

3. Erb RE, Steele JR, Nance EP Jr, Edwards JR. Traumatic anterior dislocation of the hip: spectrum of plain film and CT findings. AJR Am J Roentgeno/ 1995;165:1215-19.

4. Espinosa N, Beck M, Rothenfluh DA, Ganz R, Leunig M. Treatment of femoroacetabular impingement: preliminary results of labral refixation: surgical technique. $J$ Bone Joint Surg [Am] 2007;89-A(Pt 1 Suppl 2):36-53.

5. Tönnis D, Heinecke A. Acetabular and femoral anteversion: relationship with osteoarthritis of the hip. J Bone Joint Surg [Am]1999;81-A:1747-70.
6. Brooker AF, Bowerman JW, Robinson RA, Riley LH Jr. Ectopic ossification following total hip replacement: incidence and a method of classification. J Bone Joint Surg [Am] 1973;55-A:1629-32.

7. Ficat $\mathbf{P}$, Arlet J. Pre-radiologic stage of femur head osteonecrosis: diagnostic and therapeutic possibilities. Rev Chir Orthop Reparatrice Appar Mot 1973;59(Suppl 1):2638 (in French).

8. Harris WH. Traumatic arthritis of the hip after dislocation and acetabular fractures: treatment by mold arthroplasty: an end-result study using a new method of result evaluation. J Bone Joint Surg [Am] 1969;51-A:737-55.

9. Haddad RJ, Cook SD, Brinker MR. A comparison of three varieties of noncemented porous-coated hip replacements. J Bone Joint Surg [Br] 1990;72-B:2-8.

10. Bellamy N, Buchanan WW, Goldsmith CH, Campbell J, Stitt LW. Validation study of WOMAC: a health status instrument for measuring clinically important patient relevant outcomes to antirheumatic drug therapy in patients with osteoarthritis of the hip or knee. J Rheumatol 1988;15:1833-40.

11. Ware J Jr, Kosinski M, Keller SD. A 12-item short-form health survey: construction of scales and preliminary tests of reliability and validity. Med Care 1996;34:22033.

12. Zahiri CA, Schmalzried TP, Szuszcewicz ES, Amstutz HC. Assessing activity in joint replacement patients. J Arthroplasty 1998;13:890-5.

13. Yue JJ, Wilber JH, Lipuma JP, et al. Posterior hip dislocations: a cadaveric angiographic study. J Orthop Trauma 1996;10:447-54.

14. Epstein HC. Posterior fracture-dislocations of the hip: long-term follow-up. J Bone Joint Surg [Am] 1974;56-A:1103-27

15. Stewart MJ, Milford LW. Fracture-dislocation of the hip: an end-result study. $J$ Bone Joint Surg [Am] 1954;36-A:315-42.

16. Hougaard K, Thomsen PB. Traumatic posterior dislocation of the hip: prognostic factors influencing the incidence of avascular necrosis of the femoral head. Arch Orthop Trauma Surg 1986;106:32-5.

17. Sahin V, Karakas ES, Aksu S, et al. Traumatic dislocation and fracture-dislocation of the hip: a long-term follow-up study. J Trauma 2003;54:520-9.

18. Canale ST, Manugian AH. Irreducible traumatic dislocations of the hip. J Bone Joint Surg [Am] 1979;61-A:7-14.

19. Paterson I. The torn acetabular labrum: a block to reduction of a dislocated hip. $J$ Bone Joint Surg [Br] 1957;39-B:306-9.

20. Hunter GA. Posterior dislocation and fracture-dislocation of the hip: a review of fiftyseven patients. J Bone Joint Surg [Br] 1969;51-B:38-44.

21. Slatis $\mathbf{P}$, Latvala A. Irreducible traumatic posterior dislocation of the hip. Injury 1974;5:188-93

22. Tannast M, Mack PW, Klaeser B, Siebenrock KA. Hip dislocation and femoral neck fracture: decision-making for head presentation. Injury 2009;40:1118-24.

23. Gautier E, Ganz K, Krugel N, Gill T, Ganz R. Anatomy of the medial femoral circumflex artery and its surgical implications. J Bone Joint Surg [Br] 2000;82-B:679-83.

24. Keel M, Eid K, Isler B, Trentz $\mathbf{0}$, Ertel W. The role of surgical hip dislocation in the treatment of acetabular and femoral head fractures. Eur J Trauma 2005;31:138-47.

25. Ganz R, Gill TJ, Gautier E, et al. Surgical dislocation of the adult hip a technique with full access to the femoral head and acetabulum without the risk of avascular necrosis. J Bone Joint Surg [Br] 2001;83-B:1119-24.

26. Siebenrock KA, Gautier E, Woo AK, Ganz R. Surgical dislocation of the femoral head for joint debridement and accu4rate reduction of fractures of the acetabulum. $J$ Orthop Trauma 2002;16:543-52.

27. Espinosa N, Rothenfluh DA, Beck M, Ganz R, Leunig M. Treatment of femoroacetabular impingement: preliminary results of labral refixation. J Bone Joint Surg [Am] 2006;88-A:925-35.

28. Henle P, Kloen P, Siebenrock KA. Femoral head injuries: which treatment strategy can be recommended? Injury 2007;38:478-88.

29. Siebenrock KA, Gautier E, Ziran BH, Ganz R. Trochanteric flip osteotomy for cranial extension and muscle protection in acetabular fracture fixation using a KocherLangenbeck approach. J Orthop Trauma 1998;12:387-91.

30. Kim YT, Azuma H. The nerve endings of the acetabular labrum. Clin Orthop 1995;320:187-81.

31. Ferguson SJ, Bryant JT, Ganz R, Ito K. An in vitro investigation of the acetabular labral seal in hip joint mechanics. J Biomech 2003;36:171-8.

32. Frankel A, Booth RE Jr, Baldestron RA, Cohn J, Rothman RH. Comlpications of trochanteric osteotomy: long-term implications. Clin Orthop 1993;288:209-13.

33. Ritter MA, Gioe TJ, Stringer EA. Functional significance of nonunion of the greater trochanter. Clin Orthop 1981;159:177-82.

34. Schneeberger AG, Murphy SB, Ganz R. The trochanteric flip osteotomy. Oper Orthop Traumatol 1997:9:1-15 (in German).

35. Bastian JD, Wolf AT, Wyss TF, Notzli HP. Stepped osteotomy of the trochanter for stable, anatomic refixation. Clin Orthop 2009;467:732-8. 